Nat. Hazards Earth Syst. Sci. Discuss., doi:10.5194/nhess-2016-141, 2016

Manuscript under review for journal Nat. Hazards Earth Syst. Sci.

Published: 27 June 2016

(c) Author(s) 2016. CC-BY 3.0 License.

\title{
Data-driven Flood Analysis and Decision Support
}

\author{
Meng-Han Tsai ${ }^{1}$, Er-Xuan Sung ${ }^{2}$, Shih-Chung Kang ${ }^{2}$ \\ ${ }^{1}$ Center for Weather Climate and Disaster Research, Taipei, 10617, Taiwan \\ ${ }^{2}$ Department of Civil Engineering, National Taiwan University, Taipei, 10617, Taiwan \\ 5 Correspondence to: Shih-Chung Kang (sckang@ntu.edu.tw)
}

\begin{abstract}
Flood management is a critical issue when facing natural disasters. In current practice, the evaluation of potential threat areas is a multi-disciplinary task. It requires much communication and coordination between institutions such as the meteorological unit and hydrological unit, which makes the process time-consuming and less efficient. This study developed a system called FloodViz, which integrates all the associated tasks. FloodViz collects the rainfall forecasts from the

10 meteorological agency, analyzes the datasets of rainfall forecasts using the rainfall threshold to evaluate the potential flood areas, and then organizes the results through data visualization to make them user-friendly for decision makers. To validate FloodViz, we tested this system during Typhoon Feng-wong. The results showed that FloodViz can reduce the time spent during the flood management process by 17 minutes. Based on the results, FloodViz can improve the operating efficiency of decision-making and help decision makers in their flood response.
\end{abstract}

15 Keywords. Flood forecasting system, decision support system, rainfall threshold, flood management

\section{Introduction}

Flooding is a common natural disaster threatening human lives and wealth in both western and eastern worlds. Jha et al. (2012) reported that 178 million people around the world suffered from floods and the estimated total economic loss exceeded US $\$ 40$ billion in 2010. In Taiwan, floods are common natural hazards that cause damage and the loss of lives in

20 both urban and rural areas. Over a half century ago, the flood on 7 August 1959 caused severe damage on the land structure and a total of 1300 casualties (Xie and Zhang, 2012). This event pushed the government to invest more on the construction of structural protection measures such as spillways and dams, and non-structural measures such as research on flood simulation models.

Flood simulation models are custom computer programs that can evaluate the consequences of floods. Specialists enter

25 the actual initial conditions of the target watershed and begin the simulation several days in advance of potential floods. The results of the simulation can support practitioners to make effective decisions to defend against floods in order to reduce the damage to human lives and properties. In the past decades, as computer technology grew rapidly, it has been possible to receive more accurate simulated flood consequences in less time. Moreover, computers can now conduct more complex analyses of flood-related issues, such as the socioeconomic impact, to provide more information to support flood decisions. 
Nat. Hazards Earth Syst. Sci. Discuss., doi:10.5194/nhess-2016-141, 2016

Manuscript under review for journal Nat. Hazards Earth Syst. Sci.

Published: 27 June 2016

(c) Author(s) 2016. CC-BY 3.0 License.

Flood simulation modeling can provide a preview of flood consequences. However, in reality, when conducting flood decision-making using the flood simulation results, decision makers need to process and comprehend a vast amount of information under high time pressure in order to determine the strategies. Some studies have pointed out that the information from flood simulation is too sophisticated and most of the information is not useful for decision-making. Since then, studies

5 have identified the actual requirements of decision makers during the flood management process, and have proposed another simulation mechanism that produces only the information that meets these requirements.

According to Kundzewicz's (2013) report, a common flood management strategy includes four crucial components: flood alerts, forecasts, warnings, and responses. Flood alerts are usually issued several days before a potential event based on meteorological measures, while flood forecasts are produced by mathematical models that convert data, such as rainfall

10 measured by either rain gauges or radars, into river discharge for a further assessment of the forthcoming flooding. If some of the regions were confirmed as high-risk zones, decision makers would judge whether to issue flood warnings to these regions to help residents to avoid flood damage. Therefore, the most crucial pieces of information for decision makers are where the high-risk regions are and how severe the condition is. For example, a region located in the south of Taiwan where the flooding might take place in 3 hours according to the scientific evaluation. With this information, decision makers can decide to either evacuate the villages or dispatch enough pumps to the site for defense purpose.

In current practices of flood management in Taiwan, when the Central Weather Bureau (CWB) observes a typhoon or an extreme rain event, the Central Emergency Operation Center (CEOC) will be established by the Executive Yuan to coordinate each of the authorities concerned for flood prevention and response. CWB and the Water Resource Agency (WRA) will organize an operation team to provide meteorological and hydrological information such as the typhoon's

20 predicted path, rainfall forecasts, river discharge monitoring, etc. The chief executive of the Executive Yuan is in charge of making decisions. A consulting team consisting of meteorology and hydrology specialists is formed to assist the decisionmaking. Meteorologists are in charge of predicting the typhoon's track and forecasting rainfall distribution. Hydrologists are in charge of monitoring the river discharge, controlling the discharge of flood inflow for each reservoir, and evaluating the possibility of the occurrence of flooding for the nineteen cities and their districts. This information is then integrated into a

25 PowerPoint file as the flood forecasting report. The CEOC holds meetings four times per day and the decision maker decides which strategies to use for flood prevention and response after the discussion. In reality, the current practice can still be improved in its efficiency. For example, obtaining a flood risk map requires many manual processes; first the specialists input the initial condition parameters such as rainfall data and simulation periods, and then execute the computational model. After several minutes, they receive a list that contains the locations of potential flooding cities and their districts, as well as 30 the severity of floods. Finally, they produce a PowerPoint report to display this information on a map. This process is repeated to draw the potential flood maps in different simulation periods. The total work time is approximately half to one hour depending on the complexity of the listing objects. There are three main drawbacks for the current method. First, the flood forecast results presented in the decision stage lack instantaneity. Since this is a time-sensitive task, information instantaneity would affect the accuracy of the flood forecast. Second, too many manual processes being involved would 
Nat. Hazards Earth Syst. Sci. Discuss., doi:10.5194/nhess-2016-141, 2016

Manuscript under review for journal Nat. Hazards Earth Syst. Sci.

Published: 27 June 2016

(c) Author(s) 2016. CC-BY 3.0 License.
Natural Hazards o

and Earth System

Sciences

Discussions

(c) (i)

reduce the accuracy of the information. Any missing or misplaced data would make the process inefficient, and sometimes lead to incorrect decisions. Finally, although the paper-based report contains much useful information, it has been shown to be less effective in communicating information.

To improve the flood management process, we proposed a system that aims to overcome the aforementioned drawbacks.

5 The system is composed of three modules: (1) data processing, (2) flood forecasting, and (3) visualization. The first module, data processing, is in charge of data acquisition and data mapping. Rainfall data is collected from weather radars, and then data mapping is conducted before delivering to the second module. The second module, flood forecasting, integrates the existing workflow to conduct flood forecasts in an automatic manner. The third module, visualization, produces flood forecast results that are consistent with the flood decision-making requirements. By using this system, decision makers can rapidly grasp the information about areas at risk and develop strategies to mitigate flood damage.

\section{Literature Review}

\subsection{Wireless Sensor Network}

A number of studies have addressed the issue of disaster management from different aspects. Some studies have used specific sensors to record the rainfall figures, which are then compared to the predefined critical value using self-developed

15 computer programs. Mantas et al. (2015) developed a system called the Tropical Rainfall Measuring Mission Explorer, which adopts satellite rainfall estimates and river gauge measurements to provide information and a user-friendly interface for decision makers. Klug \& Kmoch (2014) purposed a concept using Wireless Sensor Networks and Web Technology to collect field observation in real-time for operation decision-making. Similarly, Horsburgh et al. (2009) provided an optimized framework to collect, process, and visualize data from the field. However, the aforementioned research did not

20 report the usability and performance, and therefore it is not possible to validate whether these improvements will benefit the flood management process.

\subsection{Early Warning System}

For defending against flood-related disasters, effective Early Warning Systems (EWS) are commonly adopted to support decision-making in the flood management process (Cavallo and Ireland, 2014). He et al. (2014) constructed a

25 warning platform for Hunan province in China that integrated meteorological and hydrological data from the relevant authorities. This platform can deliver warning messages to residents automatically via telephone, fax, radio broadcast, and SMS. In Spain, Cabañas et al. (2011) implemented a flood forecasting system for reservoir management to enhance the early flood warning procedure. In Japan, Limlahapun \& Fukui (2014) determined the relationship between water-level and rainfall in the Chubu region by analyzing the river network, and proposed a system to deliver the early-warning message via Email.

30 These studies have yielded global solutions to improve the performance of flood management; however, warning message auto-delivery systems might not be applicable to all countries in the world. At least in Taiwan, cell phones or computers 
Nat. Hazards Earth Syst. Sci. Discuss., doi:10.5194/nhess-2016-141, 2016

Manuscript under review for journal Nat. Hazards Earth Syst. Sci.

Published: 27 June 2016

(c) Author(s) 2016. CC-BY 3.0 License.

have not popularized in rural areas, and therefore such digital messages would never reach the target areas. In this situation, the aforementioned systems would not be reliable.

\subsection{Geological Information System}

Using the Geological Information System (GIS) to render flood-related information on a spatial basis to support

5 decisions is another widely used solution in the flood management domain. In Malaysia, Saher et al. (2014) developed a geodatabase for the Pahang river basin to support the administrative-level planning of flood mitigation. One of the advantages of GIS technology is visualization, which enables more efficient comprehension of the information while dealing with multidimension information. However, in some cases the authors have integrated too much information at once in the GIS layout window. For example, Jern (2003) designed a viewer for a flood forecasting system which utilized multiple frames to render

10 the rainfall, positions of rain gauges, and water level. In order to obtain the required information, users need to spend a long time to perform several manipulations on this interface.

\section{Research Goals}

For flood management, lead time and flood forecast accuracy are the major concerns. In order to improve current flood management practices, especially the decision-making process, it is necessary to minimize the number of manual processes

15 required when performing flood forecasts or flood simulation. Hence, we proposed a system, named FloodViz, to replace unnecessary manual work. This involves using computer-programming technology to automate the whole flood forecasting process. To realize our goal, we collected rainfall forecast data every ten minutes. We then identified the critical rainfall that caused flooding by researching historical events to judge the flood potential for each city and its districts according to the rainfall forecasts. Our other goal was the efficient presentation of information. We wish to provide decision makers with only

20 the crucial information including regions at risk and levels of flood potential. The information would be updated every ten minutes to keep the flood forecast up-to-date and presented via a well-designed visualization that reduces the decision makers' workload on comprehending complex scientific expressions. With this system, decision makers can understand the information faster and more accurately, so that they can put more effort into developing flood mitigation strategies.

\section{Methodology}

This study proposed a system with more efficient computing time and clearer information to address the difficulties of the decision-making experience. The proposed system, FloodViz, contains three modules: Data processing, flood forecasting, and visualization. The detailed operation mechanism is depicted in Figure 1. 
Nat. Hazards Earth Syst. Sci. Discuss., doi:10.5194/nhess-2016-141, 2016

Manuscript under review for journal Nat. Hazards Earth Syst. Sci.

Published: 27 June 2016

(c) Author(s) 2016. CC-BY 3.0 License.
Natural Hazards

and Earth System

Sciences

Discussions

(c) (i)

\subsection{Data Processing Module}

First, the three-day rainfall forecasts are used to evaluate flood potential for each city and its districts. The rainfall forecast is a significant reference for both meteorology and disaster prevention specialists to evaluate the threat of an upcoming typhoon, and to develop appropriate strategies to reduce social loss. In this study, rainfall data were obtained from

5 CWB, which employs the Ensemble Typhoon Quantitative Precipitation Forecasts (ETQPF) mode to provide typhoon rainfall forecasts in Taiwan. Recently, the Ensemble Prediction System (EPS) has been shown to provide valuable probability forecast information on rainfall, called quantitative precipitation forecast (QPF) (Zhang et al., 2010). Nevertheless, the typhoon track forecast was found to have positive effect on the accuracy of the rainfall forecast (Xie and Zhang, 2012). Therefore, climatologists in CWB proposed an innovative rainfall forecast model called ETQPF. ETQPF was

10 developed using both QPF derived from an EPS and a typhoon's predicted path. The Taiwan Typhoon and Flood Research Institute (TTFRI) provides QPF through executing the EPS, which gathers Weather Research and Forecasting (WRF) models from different countries and covers the whole island of Taiwan. The WRF model configuration is 5-km horizontal resolution. The typhoon's predicted path is produced by CWB. With the QPF and an estimate of the typhoon's path, similar historical cases and the observed rainfall distributions could be used to filter these QPF. Bad quality QPF would be excluded from the

15 model and good quality QPF would be selected (Hong et al., 2014). Our system was designed to automatically import the latest ETQPF into our database. Normally, ETQPF generates rainfall forecasts hourly for the next 72 hours so that flood forecasts can be updated at the same time.

Flood analysis requires data imported from hydrological or meteorological observation networks (Werner et al., 2013). These data are directed to hydrological models for flood forecasting. However, data from some external sources are usually

20 published using different formats or structures (Horsburgh et al. 2009). Different levels of inconsistency can hinder the process of flood analysis. To resolve this, data management should be performed prior to the flood analysis process. Hence, a data processing module in this study was used to make the format of the input files in line with the demand of the floodforecasting module. The data source format was transformed to another format, which can then be used by the next module. The ETQPF raw data are provided in grid format. The methodology for our flood-forecasting module was used to analyze

25 the rainfall through the reference points of each district, and bilinear interpolation was used to convert gridded rainfall to scattered rainfall distribution.

The rainfall forecasts we obtained were gridded format datasets. However, our requirement was rainfall forecasts at each rain gauge station. Therefore, we employed the Inverse Distance Weighting (IDW) interpolation to transform the formatting. Figure 2 shows a schematic diagram of the gridded rainfall data. The dotted lines represent the grid coordinate with a spatial

30 resolution of 5 kilometers in both longitude and latitude. The black points at the center of each grid represent a gridded cell. The red dot represents one of the rain gauge stations. IDW interpolation was used to return the values of rainfall forecasts associated with the location of rain gauge stations from each gridded dataset. A computer program was developed to calculate the values of rainfall forecasts for 937 rain gauge stations. We used Figure 2 as an example to illustrate the 
Nat. Hazards Earth Syst. Sci. Discuss., doi:10.5194/nhess-2016-141, 2016

Manuscript under review for journal Nat. Hazards Earth Syst. Sci.

Published: 27 June 2016

(c) Author(s) 2016. CC-BY 3.0 License.

operation of IDW interpolation in our program. At first, four of the closest grid points and their numerical values related to point $\mathrm{P}$ were identified. In the second step, the distances between the selected points and point $\mathrm{P}$ were calculated. In the third step, the distances derived from the second step were taken into account as the weight-average values, and the numerical values related to point $\mathrm{P}$ were derived. Therefore, when the gridded rainfall dataset was entered, the rainfall forecasts at each rain gauge station were obtained through the data processing module.

\subsection{Flood Forecasting Module}

In this module, the empirical rainfall threshold method, an approach for forecasting the occurrence of flooding in the near future, was used to judge whether cities had the potential for flooding based on the inputted rainfall data. With the remapped rainfall forecasts and the rainfall threshold data, the at-risk regions in the next $6,24,48$, and 72 hours can be identified.

In Taiwan, the official rainfall threshold is defined by the water resource and disaster prevention division at WRA. They use rainfall threshold to define the severity of the upcoming flooding, and the threshold is defined according to historical flood events. They assume that with the same temporal and spatial distribution, the rainfall in certain regions can reflect the potential for flooding.

Historical data including the set of available flood events and non-events were used to extrapolate the critical value for each rain gauge station. Each gauge station is responsible for the surrounding districts. Once the value of the rainfall forecast exceeds the critical value, the ministerial government department will issue a flood warning to the corresponding districts.

Table 1 illustrates the setting of the rainfall threshold. The Houanliao rain gauge station, located in Yunlin city, was taken as an example to set up 1-, 3-, 6-, 12-, and 24-hour rainfall thresholds. Wu \& Wang (2009) collected data on previous events and non-events of flooding and the accumulated rainfall to obtain the minimum rainfall-induced floods. In rain event induced flooding, a minimum 6-hour rainfall accumulation is lower than the minimum 3-hour rainfall accumulation. To make this reasonable, they considered the 3-hour and 12-hour values and made an adjustment, which is given an $*$ mark in Table 1. To achieve the purpose of efficient early warning, after receiving the value for the minimum rainfall-induced flood, a smaller value was provided to define the rainfall thresholds. The value was decided according to their specialized

25 knowledge, and the purpose of the adjustment was to minimize the response time. In order to prevent flash floods, another threshold that was $10 \mathrm{~mm}$ higher was set to ensure sufficient response time. Hence, there were two different flood warnings according to the severity: Red Warning and Orange Warning. Red Warning indicates that there are serious floods expected in specific regions. Residents in these regions are advised to evacuate immediately. Decision makers will adopt strategies such as open shelters for residents at risk and deploy manpower for disaster response. Orange Warning indicates that there is

30 a potential flood threatening residents in specific regions if it rains continually. Decision makers will request a report from the specialists in the fields in order to decide on the strategy. For reliability, the rainfall threshold is revised each year according to the latest occurrences of flood events. 
Nat. Hazards Earth Syst. Sci. Discuss., doi:10.5194/nhess-2016-141, 2016

Manuscript under review for journal Nat. Hazards Earth Syst. Sci.

Published: 27 June 2016

(c) Author(s) 2016. CC-BY 3.0 License.
Natural Hazards

and Earth System

Sciences

Discussions

(c) (1)

WRA defined 1-, 3-, 6-, 12-, 24-hour rainfall thresholds for all the districts in Taiwan with Red Warning and Orange Warning. A district may have one to three kinds of thresholds depending on different rain gauge stations in the surrounding area. To assess the flood potential at each district, we developed a computer program to automatically identify the districts where the conditions match the Red Warning or the Orange Warning by examining the latest rainfall forecasts.

\section{$5 \quad 4.3$ Visualization Module}

The visualization module performs the rendering of the flood forecast results. Visualization is a powerful way to gain knowledge from data by processing and transforming abstract data into information that can be easily understood by the user. In the practice of flood management, decision makers may have poor understanding of the analysis provided by scientists. Taking Taiwan as an example, scientists interpret the flood forecasts from their own perspective, and then they need to explain the newest flood conditions to the decision makers. By using visualization, the scientific reports are replaced by userfriendly charts or diagrams, which are then delivered to the end-user. This makes the communication between scientists and practitioners much more efficient.

The flood forecast includes time, location, and condition. One way to present such geospatial data is to use twodimension cartographic visualization (Kerren et al., 2007). There are two categories of cartographic visualization: cartogram and choropleth map. A cartogram is a map with the land area or distance substituted by some variables (i.e. population). The geometry or space of the cartogram is distorted in order to convey the information of this alternate variable. A choropleth map applies color or texture to show variables in a certain area, and use lightness and hue scale to represent the original range of numbers for end-users to learn the values and their differences from the colors. In this study, the choropleth map was employed to present the flood forecast. Colors were assigned to depict different levels of severity in the affected areas in order to catch users' attention at first glance. As shown in Figure 3 (a), areas colored red denote that the rainfall in one or more districts in that city have reached the criteria of Red Warning. Areas colored orange denote that the rainfall in one or more districts in that city have reached the criteria of Orange Warning. On the other hand, we employ "Tooltips", one of the human-computer interaction techniques, to display which districts received a warning and the severity, as shown in Figure 3 (b). The dialog box will appear when the user moves their mouse over the corresponding polygon.

\section{Implementation}

To implement our system, we used IIS 7.5 on Windows Server 2008 to run an ASP.NET application, which is the core of our system on .NET framework 4.5. As shown in Figure 4, the system comprises a user interface layer and a data layer. There are several blocks representing different components in each layer. The arrows between each pair of blocks represent the direction of data flow. The user interface layer provides several views and manipulators for users to obtain the flood forecast results. The viewers present the flood severity and effect time of each city; the manipulators offer users an interface to input the parameters such as the initial time of the forecast to obtain the corresponding results. The data layer consists of 
Nat. Hazards Earth Syst. Sci. Discuss., doi:10.5194/nhess-2016-141, 2016

Manuscript under review for journal Nat. Hazards Earth Syst. Sci.

Published: 27 June 2016

(c) Author(s) 2016. CC-BY 3.0 License.

three components. Rainfall forecasts are obtained automatically from CWB via the File Transfer Protocol (FTP) once per hour and stored in our database. The data processing module and flood forecasting module is developed by ASP.NET. The data-processing module first transforms the format of raw data into a format that can be used by our flood-forecasting module. The flood forecasting module analyzes the possible flooding districts as well as the severity of flood risk. This module then delivers the results formatted in JSON to the user interface layer for graphics rendering.

In the user interface layer, the latest information on flood severity and the locations are presented as a web page. Users can access these results via a web browser. The open source Google Maps API is used to render the skeleton map of Taiwan and the affected cites and districts, which are presented as polygon layers. To structure the polygon layers for each city, we obtained the maps in ESRI shapefile format from the Institute of Transportation, and transfer them from shapefile to JSON.

\section{Validation and Discussion}

A test was conducted to examine the usability of the system. The scenario of this test focused on the preparation of the meeting for flood decision-making. We used one of the typhoon events to validate the performance of FloodViz. Typhoon Fung-wong attacked Taiwan between September 19 and 22, 2014, causing flooding in the southern regions of Taiwan with the maximum daily rainfall of $825 \mathrm{~mm}$ observed in the Thaiwu district of Pingtung City. The two subjects involved in this test were flood management specialists. Both were asked to complete a task for reporting flood severity and affected cities to the decision maker. One of the subjects took the conventional process including downloading the rainfall forecasting data from FTP, executing the flood forecasting model by setting the initial time, then organizing the relevant information for the decision maker. The times taken for this subject to complete these tasks were 15 seconds, 30 seconds, and 16 minutes. The other subject used FloodViz to complete these tasks. Figure 5 shows that the user interface of FloodViz contains two manipulators and four views. The two manipulators, as shown in Figure 5(a), are filers for the typhoon name and the model initial time. The typhoon name filter was used as a token to request the rainfall forecasting data from the FTP folders. Model initial time was used as another token to access the exact file of the rainfall forecasting result produced once per hour. After this subject completed the aforementioned selections, the views, as shown in Figure 5(b), were rendered and the results calculated by the flood-forecasting module.

The task for the subject examining FloodViz was to open the webpage. Once the page loaded, the latest results would be presented. The whole process requires approximately 5 seconds. We conducted the test at 03:10 on 21 September, 2014 when the subject opened the webpage. As shown in Figure 5(a), the newest forecast was conducted at 03:00 on the same day. There were four maps showing flood forecasts according to the different time duration. In the order from Figure 5(b) to Figure 5(E), there were 6-hr, 24-hr, 48-hr, and 72-hr flood forecasts. As a result, Taitung city was identified as a Red Warning region by the $24-\mathrm{hr}$ forecast. The decision maker would have enough time to arrange resources to minimize potential damage from the impending disaster. In the following hours, the decision maker can take appropriate actions depending on the updated forecasts. 
Nat. Hazards Earth Syst. Sci. Discuss., doi:10.5194/nhess-2016-141, 2016

Manuscript under review for journal Nat. Hazards Earth Syst. Sci.

Published: 27 June 2016

(c) Author(s) 2016. CC-BY 3.0 License.

In summary, the visual-based flood information system FloodViz has the following benefits that can improve the operation of flood management in Taiwan:

- The system provides clear information of the potential flood areas to help decision makers identify the at-risk areas efficiently.

- The use of the system can optimize the flood management process and reduce the likelihood of errors during the process, which was previously conducted manually.

- The system delivers flood-related information using a straightforward approach — colors corresponding to the flood severity, which helps decision makers to quickly process the information.

- The use of this system can reduce the operation time between data acquisition and obtaining usable information; in other words, this system reduces the lead time for flood response, which will reduce the number of casualties and hence minimize the damage caused by flood.

\section{Conclusion and Further Research}

In this study, we developed a flood information platform called FloodViz to facilitate flood decision-making and improve the efficiency of the flood management process. The system comprises three components: a data processing module,

flood forecasting module, and visualization module. The data processing module obtains rainfall forecast data from the Central Weather Bureau, and performs pre-processing of the data. The flood-forecasting module implements the rainfall threshold method to predict the potential flooding cities and districts. Two kinds of flood warning, Red warning and Orange warning, are issued to specific districts depending on the severity. The visualization module is used to clearly present the results of the flood forecasting and to provide an interactive interface for users to explore the information they require.

The main contribution of this research is to provide clear flood decision-related information to practitioners for further judgment. By using this system, the time usually spent on manual tasks such as the transfer of information, calculation of the statistics, and creation of reports can be greatly reduced. Furthermore, the automatic process reduces the possibility of human error. The system provides an interactive interface that allows users to intuitively understand the potential for flooding in each region. A typhoon event that occurred in September 2014, Fung-wong, was used to validate the performance of

25 FloodViz. Two flood specialists were our subjects to examine the system. The purpose of the test was to evaluate the enhancement on the operating efficiency of flood management, especially in the decision making process. As a result, with the use of FloodViz, 17 minutes could be saved during the decision-making process. At this stage, this system does not yet consider river discharge in forecasting. In the future, we aim to revise our methodology to improve the accuracy of flood forecasting, and continue to test the system during real events to validate its performance and effectiveness.

\section{Acknowledgments}

The authors would like to express their appreciation of the subjects who conducted the usability test. In addition, the authors would like to acknowledge their gratitude for the funding from Taiwan's Ministry of Science and Technology under contract 
Nat. Hazards Earth Syst. Sci. Discuss., doi:10.5194/nhess-2016-141, 2016

Manuscript under review for journal Nat. Hazards Earth Syst. Sci.

Published: 27 June 2016

(c) Author(s) 2016. CC-BY 3.0 License.

(c) (i)

MOST 103-2119-M-002-011. Finally, the authors would like to thank Mr. Shih-Kun Chuang for his assistance to the development of the proposed system.

\section{References}

Cabañas, A., Garrote, L., Schwanenberg, D., González, J. and Francés, M.: An Example of Flood Forecasting and Decision5 Support System for Water Management in Spain, 8th Int. ISCRAM Conf., (May 2011), 1-5, 2011.

Cavallo, A. and Ireland, V.: Prepared for the Global Assessment Report on Disaster Risk Reduction 2015, Int. J. Disaster Risk Reduct., doi:10.1016/j.ijdrr.2014.05.001, 2014.

He, X., Zhang, D., Ren, M. and Ding, L.: The Construction Of Monitoring And Warning System For Flash Flood Defense In China, in 11th Internation Conference on Hydroinformatics, CUNY Academic Works, New York City, USA., 2014.

10 Hong, J.-S., Fong, C.-T., Hsiao, L.-F., Yu, Y.-C. and Tzeng, C.-Y.: Ensemble Typhoon Quantitative Precipitation Forecasts Model in Taiwan, Weather Forecast., 30(1), 217-237, doi:10.1175/WAF-D-14-00037.1, 2014.

Horsburgh, J. S., Tarboton, D. G., Piasecki, M., Maidment, D. R., Zaslavsky, I., Valentine, D. and Whitenack, T.: An integrated system for publishing environmental observations data, Environ. Model. Softw., 24(8), 879-888, doi:http://dx.doi.org/10.1016/j.envsoft.2009.01.002, 2009a.

15 Horsburgh, J. S., Tarboton, D. G., Piasecki, M., Maidment, D. R., Zaslavsky, I., Valentine, D. and Whitenack, T.: An integrated system for publishing environmental observations data, Environ. Model. Softw., 24(8), 879-888, doi:10.1016/j.envsoft.2009.01.002, 2009b.

Jern, M.: Web based 3D visual user interface to a flood forecasting system, in Geo-information for Disaster Management, pp. 1021-1039, Springer Berlin Heidelberg., 2005.

20 Jha, A. K., Bloch, R. and Lamond, J.: Cities and Flooding: A Guide to Integrated Urban Flood Risk Management for the 21st Century, The World Bank, Washington DC., 2012.

Kerren, A., Ebert, A. and Meyer, J.: Human-Centered Visualization Environments, edited by A. Kerren, A. Ebert, and J. Meyer, Springer Berlin Heidelberg, Berlin, Heidelberg., 2007.

Klug, H. and Kmoch, A.: Operationalizing environmental indicators for real time multi-purpose decision making and action support, Ecol. Modell., 295, 66-74, doi:10.1016/j.ecolmodel.2014.04.009, 2014.

Kundzewicz, Z. W.: Floods : lessons about early warning systems, Late Lessons from Early Warn. Syst., 379-400, 2013.

Limlahapun, P. and Fukui, H.: An Information-Systems Approach to Identifying Flood Risks in Central Japan, Int. J. Environ. Sci. Dev., 5(4), 380-386, doi:10.7763/IJESD.2014.V5.514, 2014.

Mantas, V. M., Liu, Z. and Pereira, a. J. S. C.: A web service and android application for the distribution of rainfall

estimates and Earth observation data, Comput. Geosci., 77, 66-76, doi:10.1016/j.cageo.2015.01.011, 2015.

Saher, F. N., Binti, N., Ali, M., Mohd, W., Bin, F., Ishak, W., Abdul, M. and Bin, N.: Development of an Intelligent Decision Support System for Flood Mitigation in the Pahang River, Int. J. Sustain. L. Use Urban Plan., 2(2), 1-8, 2014. 
Nat. Hazards Earth Syst. Sci. Discuss., doi:10.5194/nhess-2016-141, 2016

Manuscript under review for journal Nat. Hazards Earth Syst. Sci.

Published: 27 June 2016

(c) Author(s) 2016. CC-BY 3.0 License.

(c) (1)

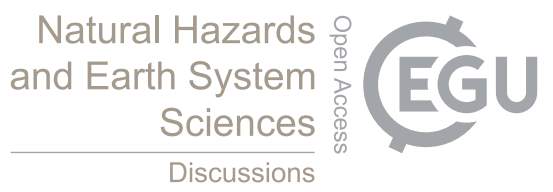

Werner, M., Schellekens, J., Gijsbers, P., van Dijk, M., van den Akker, O. and Heynert, K.: The Delft-FEWS flow forecasting system, Environ. Model. Softw., 40, 65-77, doi:10.1016/j.envsoft.2012.07.010, 2013.

Wu, D. and Wang, Y.-F.: A Research on using Critical Precipitation Value for Taiwan Inundation Warning System, in Taiwan Disaster Management Conference (In Chinese), Taipei, Taiwan., 2009.

5 Xie, B. and Zhang, F.: Impacts of Typhoon Track and Island Topography on the Heavy Rainfalls in Taiwan Associated with Morakot (2009), Mon. Weather Rev., 140(10), 3379-3394, doi:10.1175/MWR-D-11-00240.1, 2012.

Zhang, F., Weng, Y., Kuo, Y.-H., Whitaker, J. S. and Xie, B.: Predicting Typhoon Morakot's Catastrophic Rainfall with a Convection-Permitting Mesoscale Ensemble System, Weather Forecast., 25(6), 1816-1825, doi:10.1175/2010WAF2222414.1, 2010.

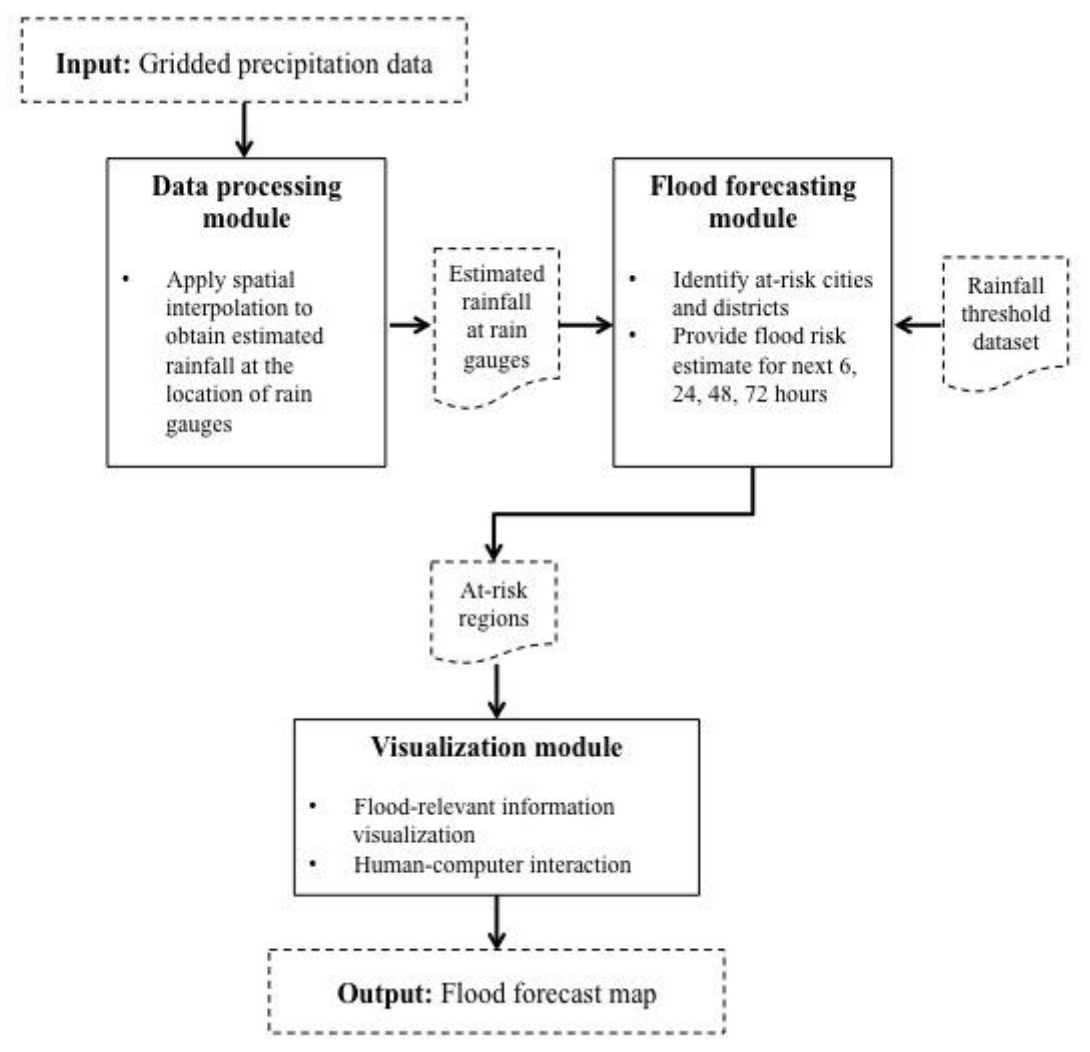

Figure 1: System Framework of FloodViz. 
Nat. Hazards Earth Syst. Sci. Discuss., doi:10.5194/nhess-2016-141, 2016 Manuscript under review for journal Nat. Hazards Earth Syst. Sci.

Published: 27 June 2016

(c) Author(s) 2016. CC-BY 3.0 License.

\section{(c) (i)}

\section{Natural Hazards and Earth System Sciences \\ Discussions}

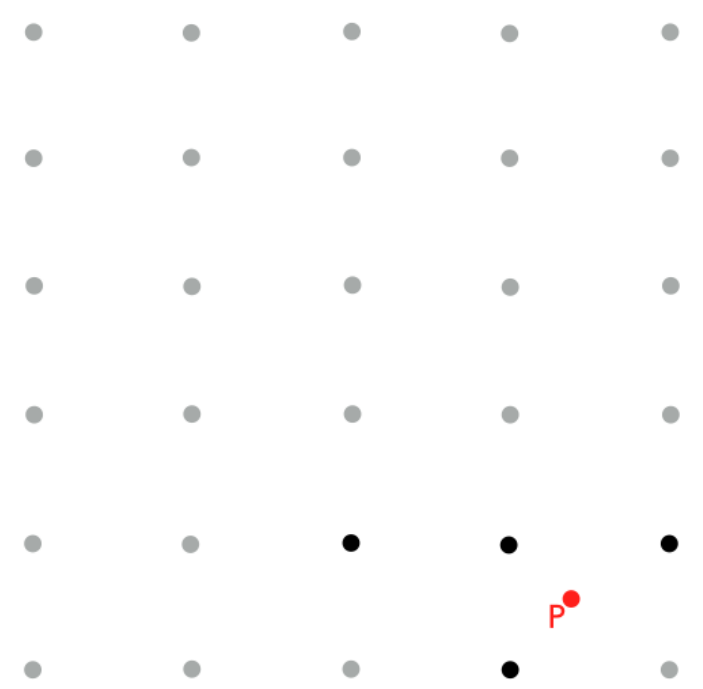

Figure 2: Schematic Diagram of the Gridded Rainfall Data.

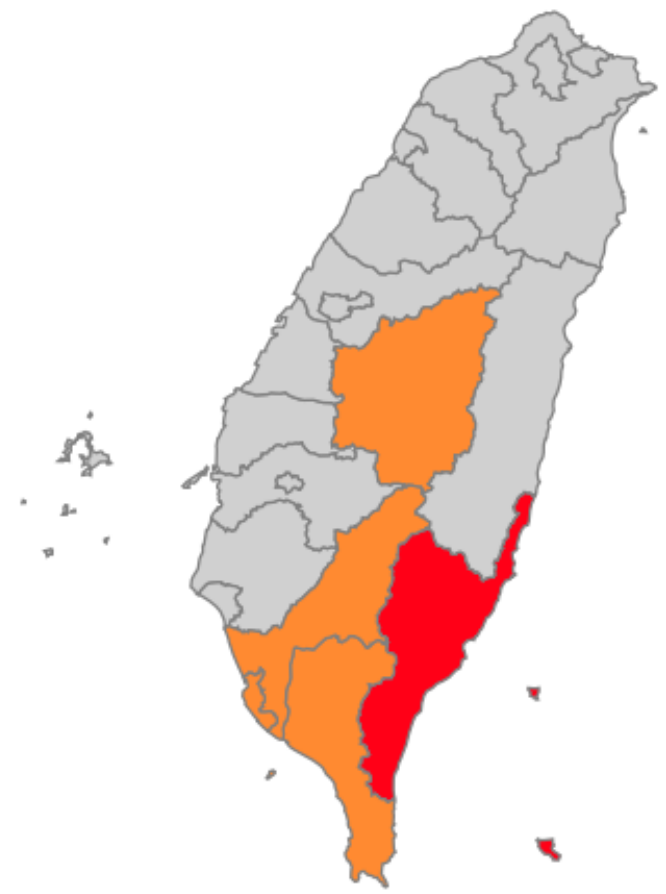

Figure 3 (a): Schematic Diagram of the Choropleth Map. 
Nat. Hazards Earth Syst. Sci. Discuss., doi:10.5194/nhess-2016-141, 2016

Manuscript under review for journal Nat. Hazards Earth Syst. Sci.

Published: 27 June 2016

(c) Author(s) 2016. CC-BY 3.0 License.

(c) (1)

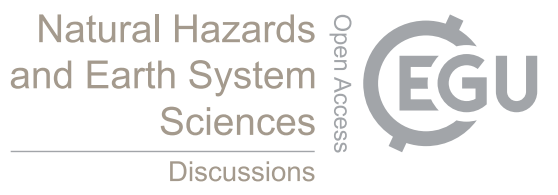

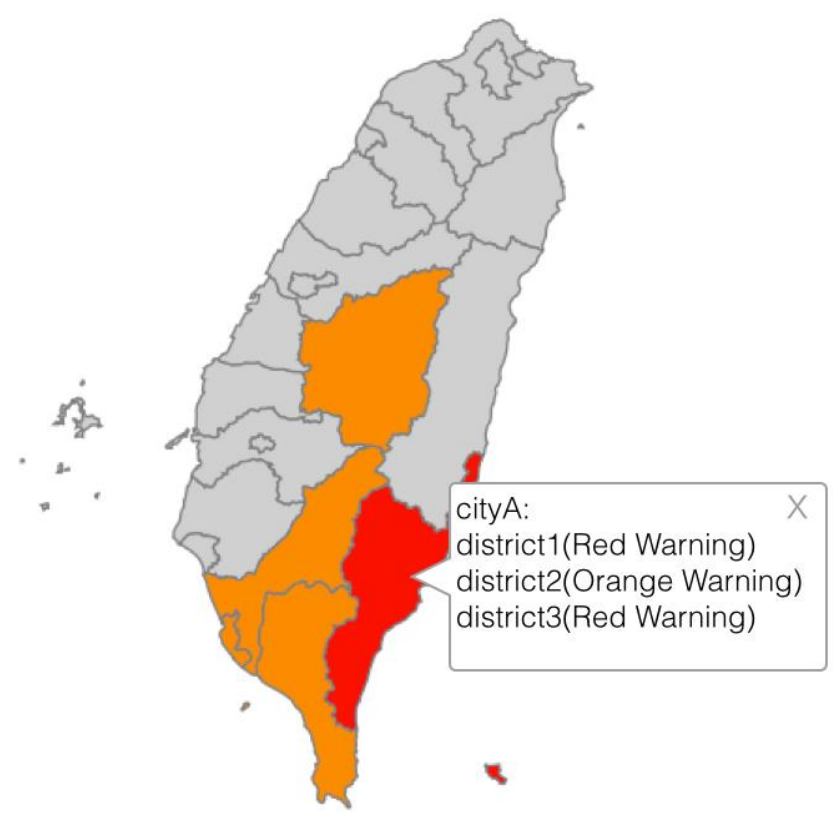

Figure 3 (b): Schematic Diagram of Tooltip.

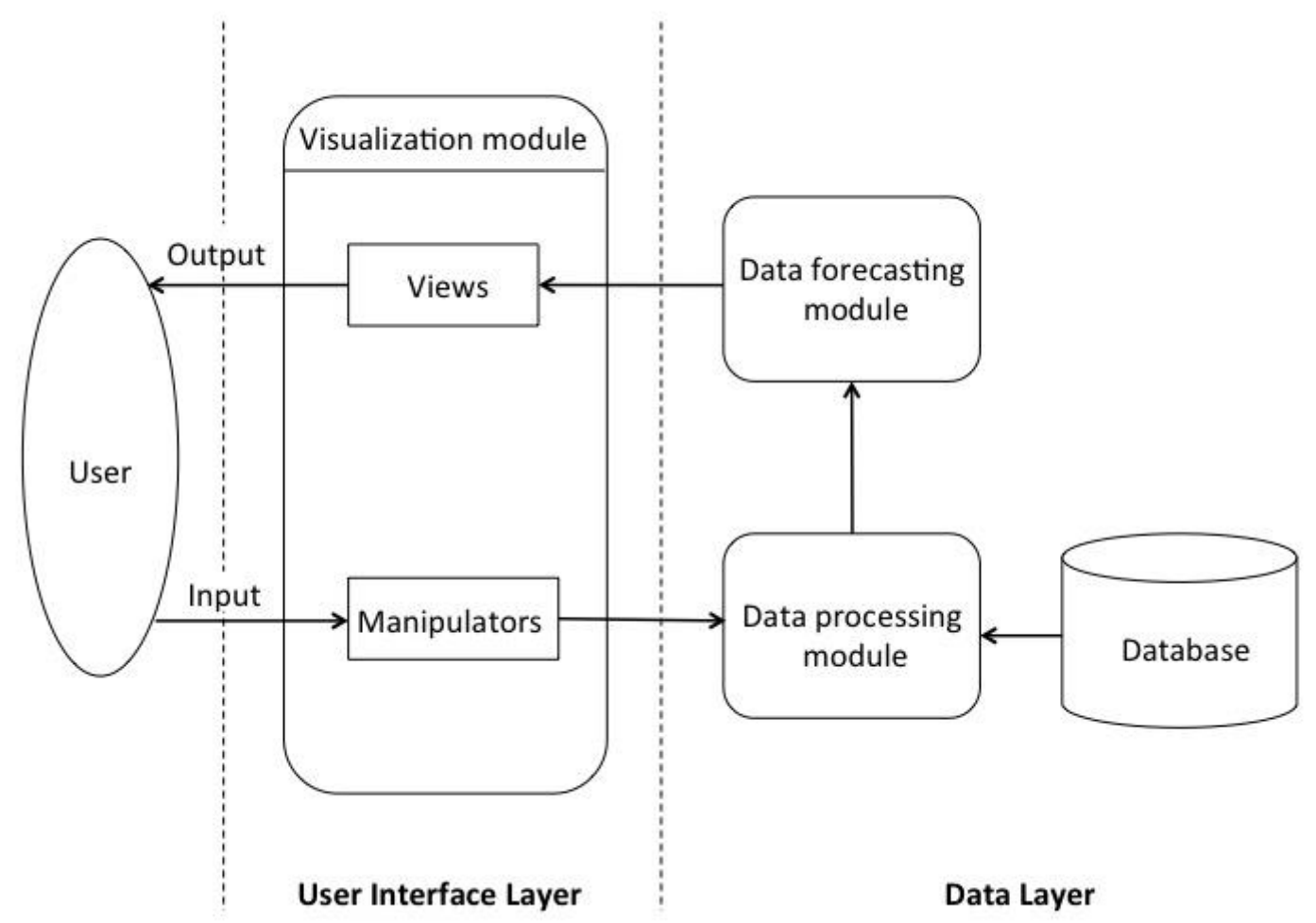


Nat. Hazards Earth Syst. Sci. Discuss., doi:10.5194/nhess-2016-141, 2016

Manuscript under review for journal Nat. Hazards Earth Syst. Sci.

Published: 27 June 2016

(C) Author(s) 2016. CC-BY 3.0 License.
Natural Hazards and Earth System

(c) $\underset{\mathrm{BY}}{(\mathrm{i}}$

Figure 4: System Architecture of the FloodViz System.

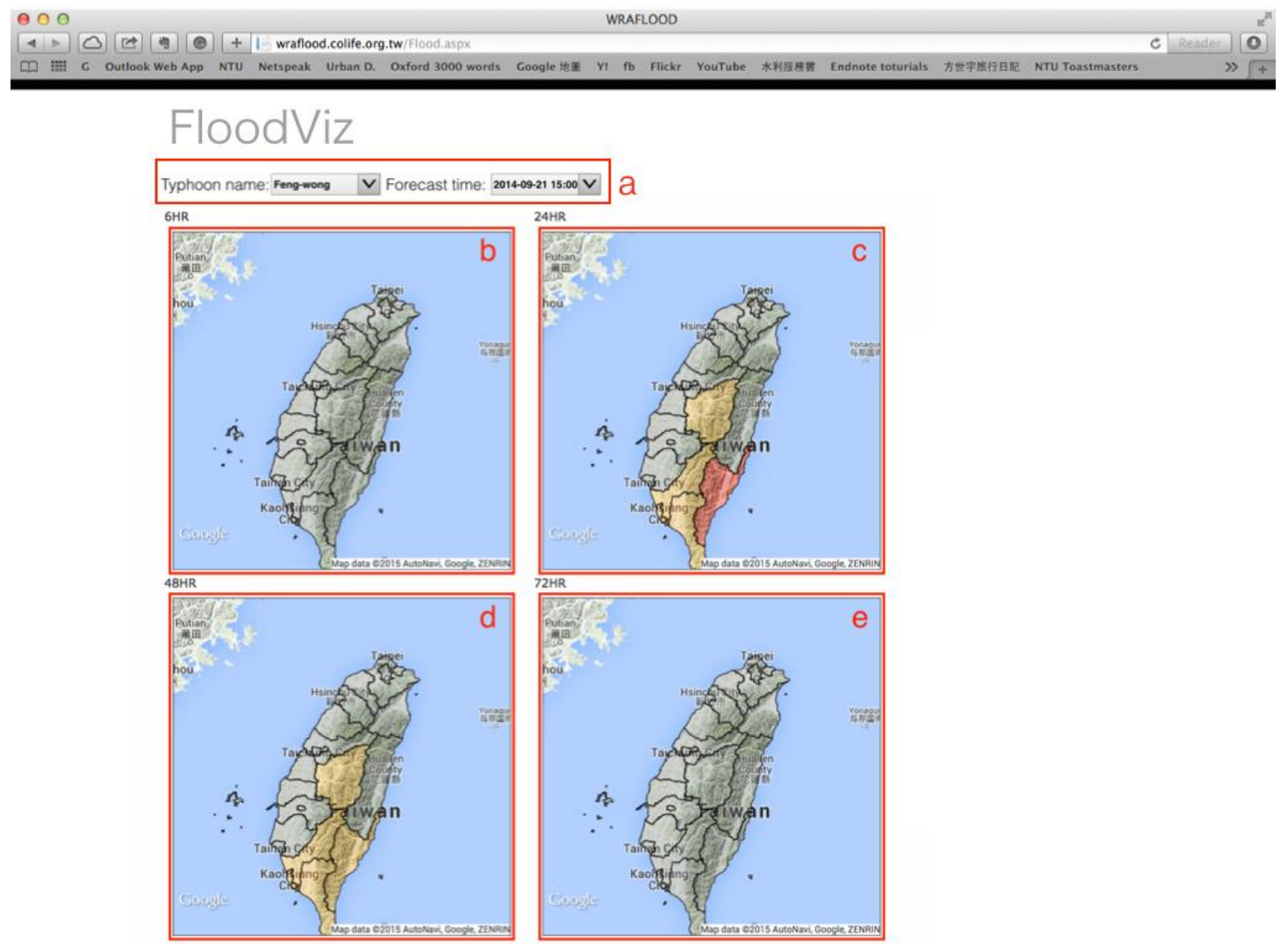

Figure 5: Overview of the User Interface of FloodViz; (a) typhoon name and model initial time filter; (b) 6-hr flood forecast; (c) 24-hr flood forecast; (d) 48-hr flood forecast; (e) 72-hr flood forecast.

\begin{tabular}{cccccccccc}
\hline $\begin{array}{c}\text { Accum. } \\
\text { Rainfall }\end{array}$ & $\begin{array}{c}\text { Rain } \\
\text { Event A } \\
(\text { hour }(\mathrm{s}))\end{array}$ & $\begin{array}{c}\text { Rain } \\
\text { Event B }\end{array}$ & $\begin{array}{c}\text { Rain } \\
\text { Event C }\end{array}$ & $\begin{array}{c}\text { Rain } \\
\text { Event D } \\
(\mathrm{mm})\end{array}$ & $\begin{array}{c}\text { Rain } \\
(\mathrm{mm})\end{array}$ & $\begin{array}{c}\text { Min. } \\
\text { Event E } \\
(\mathrm{mm})\end{array}$ & $\begin{array}{c}\text { Min. } \\
(\mathrm{mm})\end{array}$ & $\begin{array}{c}\text { Orange } \\
\text { inducing } \\
\text { Warning }\end{array}$ & $\begin{array}{c}\text { Red } \\
\text { Warning }\end{array}$ \\
\hline 1 & 13 & 18 & 56 & 24 & 55 & 13 & 55 & 30 & 40 \\
3 & 36 & 36 & 108 & 50 & 89 & 36 & 89 & 70 & 80 \\
6 & 64 & 69 & 141 & 60 & 146 & 60 & $100^{*}$ & 90 & 100 \\
12 & 113 & 86 & 146 & 82 & 226 & 82 & 113 & 100 & 110 \\
24 & 160 & 105 & 186 & 131 & 321 & 105 & 160 & 130 & 140 \\
\hline Flood event & Yes & No & Yes & No & Yes & & & &
\end{tabular}

$5 *$ After making reasonable adjustments

Table 1: Illustration of the Setting of the Rainfall Threshold using the Houanliao Rain Gauge Station as an example 